\title{
And So the Journey Continues
}

\author{
Janice Munroe
}

$\mathrm{L}$

ife is a journey. Actually, it's a veritable marathon, not just a

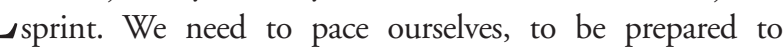
conquer the hills so that we can enjoy the vistas. Every step along the way brings new opportunities, both professionally and personally. The journey also includes challenges- the curves and bends along the path. We take up the journey because of the unknown yet exciting prospects that it holds for learning, growing, and ultimately making a difference!

Pharmacy practice is on its own journey for continuing evolution, a quest that has been and continues to be supported by CSHP. Through the CSHP 2015 initiative, hospital pharmacists are striving to expand the scope of pharmacy practice and to improve patient outcomes.

CSHP itself is undergoing an evolution of sorts through the establishment of new bylaws and the formalization of the Society's governance structure. Through the contributions of CSHP volunteer members in these efforts, CSHP will soon be "reborn"!

As individual hospital pharmacists, we are each on our own professional journey, with the destination of making a difference in the life of each and every patient under our care-to be the best pharmacists we can be. On this particular expedition, the curves and bends along the way serve to strengthen both our knowledge and our compassion.

I see my new role as CSHP's President Elect as an exciting journey that will broaden my exposure to pharmacy practice across Canada and allow me to experience new activities and meet new pharmacists. For me, it will be the ultimate opportunity for both personal and professional growth. Although it is impossible to envision what is looming ahead around those curves, I look forward to the prospects that await.
On a personal note, 10 months ago my life's journey was enriched when my grandson Kaden entered the world and began his own odyssey. I've seen how awestruck he is by the all of the people and things he sees in the world around him. His attitude has reminded me that even

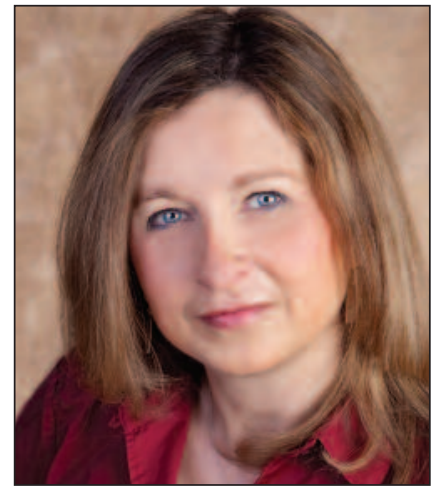
as adults, we must endeavour to hold onto this quality, this wonderment in the world around us! Like Kaden, we should remain ever inquisitive, always in search of new experiences, learning new skills, building new relationships with people, and ultimately making a difference. We need to take each step of our journey earnestly, seizing each and every opportunity to learn and grow together in our profession.

For almost 65 years, CSHP has been with us, supporting hospital pharmacists on our personal journeys. We can be confident that the Society will continue to be with us for many years to come, and that together we will continue to make a difference in patient outcomes, one personal journey at a time.

Janice Munroe, BScPharm, will take on the role of CSHP President Elect and Internal Liaison following the CSHP Annual General Meeting in August 2010 